\title{
Occupational asthma in workers of a pharmaceutical company processing spiramycin
}

\author{
JEAN-LUC MALO, ANDRÉ CARTIER \\ From the Department of Chest Medicine, Hôpital du Sacré-Coeur, Montreal, Canada
}

\begin{abstract}
After investigation of one worker with occupational asthma, all 51 employees of a pharmaceutical company processing the macrolide antibiotic spiramycin were investigated to determine the frequency of the condition and the risk factors. The antibiotic was produced for short periods four to five times a year. The first part of the investigation, conducted before a production period, consisted of the following: questionnaire, skinprick tests, blood sample, spirometry, assessment of bronchial responsiveness to methacholine, and monitoring of peak expiratory flow rates (PEF). The second part of the survey was carried out in 48 of the 51 workers during the production period, and included the same assessments except for skin testing. No FEV 1 values had changed by more than $9 \%$ or PEF by more than $19 \%$. Inhalation challenge with spiramycin was performed in 12 of the 14 individuals who had a history of occupational asthma, a provocative concentration of methacholine $\left(\mathrm{PC}_{20}\right)$ of $16 \mathrm{mg} / \mathrm{ml}$ or less, or a $\mathrm{PC}_{20}$ that fell by 2.5 fold or more during the production period (or a combination of these). Three subjects experienced immediate bronchoconstriction. All reported symptoms, and all had a fall in $\mathrm{PC}_{20}$ methacholine during the production period. It is concluded that the minimum frequency of occupational asthma in this company processing spiramycin is $4 / 51(7 \cdot 8 \%)$. The combination of a positive response to the questionnaire and a change in bronchial hyperresponsiveness during the production period appeared to be the best detector of individuals with occupational asthma, as confirmed by inhalation challenge with spiramycin.
\end{abstract}

Occupational asthma has been described in employees of pharmaceutical companies processing spiramycin. ${ }^{1-3}$ In the only epidemiological survey, ${ }^{4} 37$ of 305 workers $(12 \cdot 1 \%)$ exposed to spiramycin showed symptoms of asthma, rhinitis, or urticaria. Ten workers $(3.3 \%)$ had symptoms suggesting work related asthma but the diagnosis was not confirmed objectively. In individual cases, however, inhalation challenge with spiramycin ${ }^{1-3}$ has caused late or dual asthmatic reactions.

The aim of the present study was to determine by objective means the frequency of occupational asthma in a pharmaceutical company employing 51 workers who were intermittently exposed to spiramycin.

Address for reprint requests: Dr Jean-Luc Malo, Department of Chest Medicine, Hôpital du Sacré-Coeur, 5400 W Gouin Boulevard, Montreal, Canada H4J 1 C5.

Accepted 25 January 1988

\section{Methods}

SPIRAMYCIN PROCESSING

The company processed spiramycin five to 10 times a year for periods of one to two weeks. Nearly 30 other products were processed during the rest of the time but none of the other products has been reported as causing occupational asthma. ${ }^{5}$ None of the employees wore masks. Spiramycin powder was imported as a raw material. The departments where it was processed were sealed. Spiramycin was first weighed and processed in the reception and production departments, where three and 10 workers respectively were employed. In these departments it was judged that the heaviest exposures occurred as large quantities of spiramycin were handled freely. After each processing period the premises were cleaned thoroughly with water. Spiramycin was put into capsules in a different department, where 19 workers were exposed. The process was automated, but spiramycin powder was sometimes released into the air as capsules were broken. After each production period the department 
was cleaned, but no water was used. Quality control of the product was performed by 16 employees working in a different building. Finally, three employees worked on maintenance.

\section{EPIDEMIOLOGICAL SURVEY}

The diagnosis of occupational asthma was first suspected in one worker exposed to spiramycin. A specific inhalation challenge was carried out by exposing the individual to spiramycin for 15 minutes. This elicited a fall in $F E V_{1}$, which started at 30 minutes and was maximal ( $32 \%$ fall) 90 minutes after exposure. There was no appreciable recovery until seven and a half hours after the challenge, at which time inhaled salbutamol was given with partial recovery (to $88 \%$ of the baseline) of $\mathrm{FEV}_{1}$. It was decided to investigate the other 50 exposed employees, the following procedures being used.

\section{INITIAL ASSESSMENT}

This study was carried out two months after the last spiramycin processing period. A questionnaire, administered by a trained nurse, was based on a questionnaire recently developed by the IUAT (W W Holland, personal communication). It included questions about the personal atopic history, asthma, and smoking habits of the subjects and in addition items on asthmatic symptoms, rhinoconjunctivitis, and urticaria on exposure to spiramycin. Questions related to occupational asthma included the presence of cough, wheezing, chest tightness, dyspnoea, and nocturnal respiratory symptoms at the time of the production of spiramycin. As the questionnaire was administered two months after the last production period, thus reducing the accuracy of response to specific questions, we thought that two or more positive answers were required for considering the response suggestive of occupational asthma.

Subjects underwent skin tests by the prick method with a battery of common inhaled allergens: tree, grass, and ragweed pollens; house dust, feathers, and Dermatophagoides farinae; Alternaria spp, Aspergillus fumigatus, Hormodendrum spp; cat and dog danders (Hollister-Stier, Rexdale, Ontario; Bencard, Mississauga, Ontario); a control diluent; and histamine phosphate solution at $1 \mathrm{mg} / \mathrm{ml}$. Skin tests with spiramycin diluted in phosphate buffered saline at $0 \cdot 01,0 \cdot 1,1$ and $10 \mathrm{mg} / \mathrm{ml}$ were also performed. The mean of two perpendicular diameters of the weal reaction recorded 10 minutes after the introduction of the antigen was recorded. Spiramycin skin testing was also performed in a sample of 53 consecutive asthmatic patients seen in our outpatient clinic.

Blood was drawn for the measurement of total eosinophil numbers.

Spirometry, including the measurement of $\mathrm{FEV}_{1}$, forced vital capacity $(\mathrm{FVC})$, and the ratio $\mathrm{FEV}_{\mathrm{l}} / \mathrm{FVC}^{,}$, was performed with a dry spirometer (Vitalograph Vitalograph Ltd, London) according to the criteria of the American Thoracic Society. ${ }^{6}$ Serial monitoring of peak expiratory flow rates (PEF) was performed with the Wright mini peak flow meter (Clement Clarke International, London). Subjects were asked to record three PEF values four times a day (on rising, at lunch, at the end of the workshift, and at bedtime) and $\vec{o}$ whenever they had chest symptoms. The greater of the two most reproducible $( \pm 20 \mathrm{l} / \mathrm{min})$ values at each time ${ }_{\sigma}$ was kept for analysis. PEF was monitored during the week preceding exposure to spiramycin and during the production period, including the weekend.

Bronchial responsiveness to inhaled methacholineir was assessed according to the method described by Cockcroft et al, except for the use of methacholine ${ }_{0}$ instead of histamine. After baseline assessment of spirometric values, each subject inhaled phosphate $\overrightarrow{\vec{Z}}$ buffered saline at tidal volume breathing for twow minutes with the Wright nebuliser (output $0.14 \mathrm{ml} /$ min; mean diameter of inhaled particles $1 \cdot 3 \mu \mathrm{m}$ ). $\mathrm{FEV}_{100}$ was assessed 30 and 90 seconds after the end of nebulisation. Increasing doubling concentrations of methacholine from 0.03 to $128 \mathrm{mg} / \mathrm{ml}$ (if the subject had a history of asthma or occupational asthma or both) or from 2 to $128 \mathrm{mg} / \mathrm{ml}$ (if no such history was气 obtained) were nebulised. The test was stopped when $\mathbb{D}_{\mathbb{L}}$ the $\mathrm{FEV}_{1}$ had decreased by $20 \%$ or more or when the highest concentration had been nebulised. The test5 was not done in subjects with a history of coronarys artery disease, hypertension, or epilepsy.

\section{SECOND ASSESSMENT}

A second assessment was undertaken during the spiramycin production period, which lasted for five too 10 days, depending on the department. Three subjects included in the first assessment were absent at this time? because of holidays, minor surgery, and upper res -3 piratory tract infection.

At least one day after the onset of exposure each subject was given a short questionnaire incorporating을 some questions from the initial questionnaire and inquiring about any cough, shortness of breath, tightness in the chest, wheezing, or rhinoconjunctivitis symptoms during the period of processing. As this questionnaire was administered during the productiono period, thus improving the accuracy of response to specific answers, we considered that we had to investigate every individual who reported at least one complaint. This differed from the initial survey ques-0 tionnaire, administered two months after the lasto production period, in which two or more positive answers were required (see above). Spirometry wasi repeated and blood taken for a total white cell ancoeosinophil count. Bronchial responsiveness to metha- 
choline was assessed and serial PEF measurements were made as before for the total production period.

Total dust exposures were measured by a sample carried by one worker in the respective department and collected on PVC filters of $0.8 \mu \mathrm{m}$ pore size, a Dupont P-2500 volume pump being used. Sampling time varied from two to four hours, covering the entire processing period.

\section{THIRD ASSESSMENT: SPIRAMYCIN INHALATION}

\section{TESTS}

Spiramycin inhalation tests were performed in a challenge room of the hospital laboratory as described by Pepys and Hutchcroft. ${ }^{8}$ On the first day the subject was asked to tip lactose dust from one tray to another for 30 minutes. FEV , was recorded before the exposure, every 10 minutes for one hour after the challenge, then every 30 minutes for one hour, and hourly up to eight hours after the challenge. A methacholine inhalation test was carried out at the end of the day. On the second day neat spiramycin was used instead of lactose for the following intervals: five, 15 , and 45 seconds and two minutes for two consecutive exposures. FEV , was recorded immediately and 10 minutes after the end of each exposure, and then at the same intervals as on the day of exposure to lactose. The exposure was stopped if the FEV had dropped by $20 \%$ or more. If no appreciable change in $\mathrm{FEV}_{1}$ had been recorded that day, exposure was prolonged to 30 minutes on a third day. A methacholine inhalation test was repeated at the end of that day.

\section{ANALYSIS OF RESULTS}

Reference values for $F E V_{1}$ and $F E V_{1} / F V C$ were obtained from Knudson et al. ${ }^{9}$ Daily changes in PEF were expressed as [(highest value - lowest value)/ highest value] $\times 100$. Methacholine dose-response curves were drawn on a non-cumulative semilogarithmic scale. The concentration causing a $20 \%$ fall in $\mathrm{FEV}_{1}\left(\mathrm{PC}_{20}\right)$ was obtained by interpolation.

\section{Results}

\section{INITIAL ASSESSMENT}

Details of the subjects are given in table 1. All employees answered the questionnaire. Eleven subjects had at least one positive answer to one of four questions on wheezing, chest tightness, dyspnoea, and nocturnal cough. Twelve subjects had at least one positive answer to questions related to occupational asthma - that is, cough, wheezing, chest tightness, dyspnoea, and nocturnal respiratory symptoms at the time of the production of spiramycin. Six subjects had a "positive" questionnaire (two or more positive answers) suggesting occupational asthma. Twenty one
Table 1 Clinical and lung function data on the 51 workers

\begin{tabular}{|c|c|c|}
\hline & $\begin{array}{l}\text { First } \\
\text { assessment }\end{array}$ & $\begin{array}{l}\text { Second } \\
\text { assessment }\end{array}$ \\
\hline 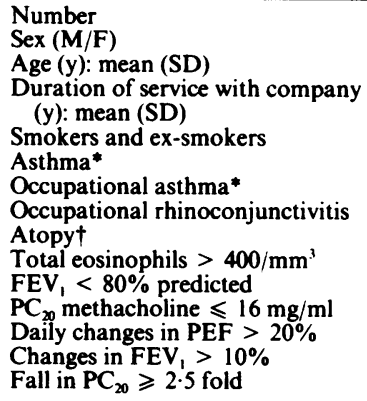 & $\begin{array}{l}51 \\
25 / 26 \\
37(10) \\
10(8) \\
26(51 \%) \\
4(8 \%) \\
6(12 \%) \\
21(41 \%) \\
20 / 49(41 \%) \\
3(6 \%) \\
3(6 \%) \\
9 / 47(19 \%) \\
0 \\
-\end{array}$ & $\begin{array}{l}48 \\
23 / 25 \\
36(10) \\
10(8) \\
23(48 \%) \\
4(8 \%) \\
9(19 \%) \\
15(31 \%) \\
18 / 46(39 \%) \\
4(8 \%) \\
3(6 \%) \\
6 / 43(14 \%) \\
0 \\
0 \\
7 / 42(16 \cdot 7 \%)\end{array}$ \\
\hline
\end{tabular}

*As defined from the questionnaire.

†At least one immediate skin reaction to common inhaled allergens (see text).

$\mathrm{PC}_{20}$ methacholine, concentration of histamine provoking a $20 \%$ fall in $\mathrm{FEV}_{1}$; PEF, peak expiratory flow.

subjects had symptoms of rhinoconjunctivitis after exposure to spiramycin.

Skin tests could be interpreted in only 49 subjects, as two subjects showed dermographism. Twenty subjects had at least one immediate reaction to common inhaled allergens. Results of skin test responses to spiramycin could not be interpreted as some individuals had reactions at concentrations of 0.01 and $0.1 \mathrm{mg} / \mathrm{ml}$, but no reaction at 1 and $10 \mathrm{mg} / \mathrm{ml}$. This was also the case in seven of 53 adult individuals with asthma who underwent skin testing with spiramycin in our outpatient clinic, and who had positive immediate reactions, generally at low concentrations of spiramycin.

Three subjects had an $\mathrm{FEV}_{1}$ below $80 \%$ of the predicted value and nine subjects had bronchial hyperresponsiveness to methacholine $\left(\mathrm{PC}_{20} \leqslant 16 \mathrm{mg}\right.$ / $\mathrm{ml}$ ). The mean daily change in PEF was $7.3 \%$ (SD $3.5 \%)$. None of the subjects demonstrated a change in PEF of more than $20 \%$. $^{10}$

\section{SECOND ASSESSMENT}

Forty eight subjects were seen during the production period. One of the three who were absent had a history suggesting occupational asthma at the initial assessment. Nine subjects reported symptoms suggesting occupational asthma on this occasion - that is, at least one positive answer regarding cough, wheezing, chest tightness, dyspnoea, and nocturnal respiratory symptoms at the time of the production of spiramycin. Four of these nine subjects had had a "positive" questionnaire before the production period. Fifteen subjects had a history of rhinoconjunctivitis. Six subjects had a $\mathrm{PC}_{20}$ of $16 \mathrm{mg} / \mathrm{ml}$ or less, and seven had a 2.5 fold or greater fall in $\mathrm{PC}_{20}$ (the between day reproducibility of 
Table 2 Characteristics of the three workers with occupational asthma

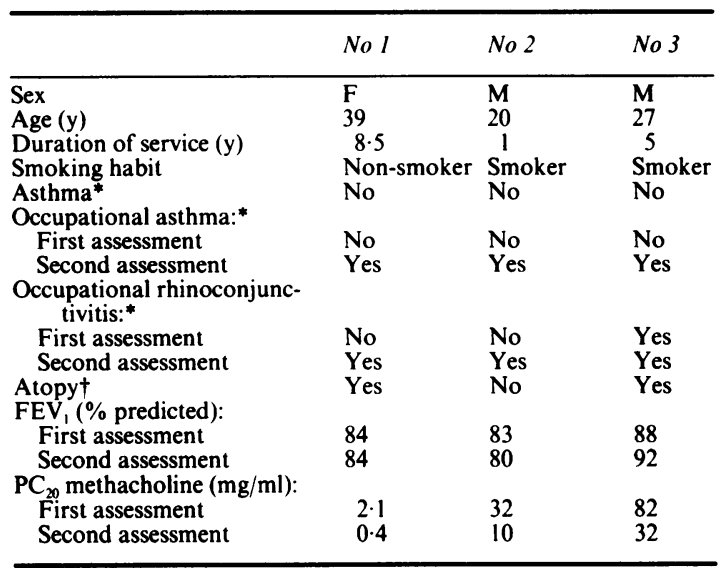

*As defined from the questionnaire.

†At least one immediate skin reaction to common inhaled allergens (see text).

$\mathrm{PC}_{20}$, see footnotes to table 1 .

the test is $3 \cdot 2^{\prime \prime}$ in our laboratory). The mean daily change in PEF was $6.9 \%$ (SD $3.0 \%$ ). No subject had a change in PEF of more than $20 \%$.

The concentration of particles was $1 \cdot 14 \mathrm{mg} / \mathrm{m}^{3}$ in the reception department, and varied from 0.54 to 2.33 $\mathrm{mg} / \mathrm{m}^{3}$ in the capsule department.

\section{FINAL ASSESSMENT}

Inhalation challenges with spiramycin were performed in all subjects who had a history suggesting occupational asthma at the first or second assessment, a $\mathrm{PC}_{20}$ of $16 \mathrm{mg} / \mathrm{ml}$ or less, or a 2.5 fold or greater fall in $\mathrm{PC}_{20}$ at the time of the second assessment. Fourteen subjects met one or more of these criteria. Challenge with spiramycin was refused by one subject who had a suggestive history but whose $\mathbf{P C}_{20}$ had increased from 16 to $64 \mathrm{mg} / \mathrm{ml}$ at the time of the processing; and it was not performed in a symptom free new employee, whose $\mathrm{PC}_{20}$ fell from $>128$ to $28 \mathrm{mg} / \mathrm{ml}$ and who had been exposed to spiramycin for the first time. The characteristics of the three subjects who had a positive response to inhalation challenges are shown in table 2. One subject had reported only one respiratory symptom before the production period, and had therefore been considered to have a "negative" questionnaire for occupational asthma according to the criteria set at that time (see above). All three subjects reported symptoms at the time of exposure. Two of the three subjects had a $\mathbf{P C}_{20}$ methacholine of $16 \mathrm{mg} / \mathrm{ml}$ or less at the time of the production period, and in the third subject the $\mathrm{PC}_{20}$ fell 2.5 fold. The inhalation challenges caused an immediate fall in FEV, in the three subjects, with recovery in the first hour followed by a mild late
Malo, Cartierō

reaction for subject 1 , no appreciable recovery in $x$. subject 2 , and recovery after four hours in subject $3 \overrightarrow{\overline{\bar{S}}}$ (figure). None of the subjects considered to have negative response to spiramycin had a fall in $\mathrm{PC}_{20}$ of? more than $3 \cdot 2$ fold at the end of the active challenge day.

Two of the three subjects with a $\mathrm{PC}_{20}$ of $16 \mathrm{mg} / \mathrm{ml}$ or less and a "positive" questionnaire at the time of production had a positive inhalation challenge to $\overrightarrow{0}$ spiramycin (table 3). One individual with a "positive"questionnaire but a $\mathrm{PC}_{20}$ greater than $16 \mathrm{mg} / \mathrm{ml}$ had aw positive response to challenge with spiramycin Another individual with a "positive" questionnaire and $\mathrm{PC}_{20}$ of $16 \mathrm{mg} / \mathrm{ml}$ or less had a negative response to challenge with spiramycin (table 4). The threeir subjects with a fall in $\mathrm{PC}_{20}$ and a "positive" question- $-y$ naire at the time of spiramycin production also had apositive response to the inhalation challenge. In contrast, the nine subjects who met one but not both of these criteria failed to show appreciable bronchoconstriction after laboratory exposure to spiramycin.

\section{Discussion}

Several antibiotics, including ampicillin, the cephalo sporins, tetracycline and spiramycin, have been listed among the aetiological agents of occupational asth-مै

Table 3 Correspondence between results of questionnaire and bronchial responsiveness*

\begin{tabular}{|c|c|c|c|c|c|}
\hline \multirow{2}{*}{$\begin{array}{l}\text { Answers } \\
\text { to question- } \\
\text { naire }\end{array}$} & \multicolumn{2}{|c|}{$\begin{array}{l}P C_{x y} \leqslant 16 \mathrm{mg} / \mathrm{ml}: \\
\text { Response to spiramycin } \\
\text { challenge }\end{array}$} & \multicolumn{2}{|c|}{$\begin{array}{l}P C_{y}>16 \mathrm{mg} / \mathrm{ml}: \\
\text { Response to spiramycin } \\
\text { challenge }\end{array}$} & \multirow[b]{2}{*}{ Total } \\
\hline & Positive & Negative & Positive & Negative & \\
\hline $\begin{array}{l}\text { Positive } \\
\text { Negative } \\
\text { Total }\end{array}$ & $\begin{array}{l}2 \\
0\end{array}$ & $\begin{array}{l}1 \\
4\end{array}$ & $\begin{array}{l}3 \\
4\end{array}$ & 5 & $\begin{array}{r}9 \\
40 \\
49\end{array}$ \\
\hline
\end{tabular}

*Results in employees who had either a "positive" questionnaire ( $\mathrm{n}=$ 9) or a $\mathrm{PC}_{20} \leqslant 16 \mathrm{mg} / \mathrm{ml}(\mathrm{n}=7)$, or both, and who underwento inhalation challenges with spiramycin.

$\mathrm{PC}_{20}$, see footnotes to table 1 .

Table 4 Correspondence between results of questionnaire and changes in bronchial responsiveness*

\begin{tabular}{|c|c|c|c|c|c|}
\hline \multirow{2}{*}{$\begin{array}{l}\text { Answers } \\
\text { Answers } \\
\text { to question- } \\
\text { naire }\end{array}$} & \multicolumn{2}{|c|}{$\begin{array}{l}\text { Changes in } P C_{y} \geqslant 2 \cdot 5 \\
\text { fold: } \\
\text { Response to spiramycin } \\
\text { challenge }\end{array}$} & \multicolumn{2}{|c|}{$\begin{array}{l}\text { Changes in } P C_{y}<2.5 \\
\text { fold: } \\
\text { Response to spiramycin } \\
\text { challenge }\end{array}$} & 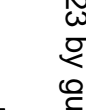 \\
\hline & Positive & Negative & Positive & Negative & Total \\
\hline $\begin{array}{l}\text { Positive } \\
\text { Negative } \\
\text { Total }\end{array}$ & $\begin{array}{l}3 \\
0\end{array}$ & $\begin{array}{l}0 \\
4\end{array}$ & 0 & 5 & $\begin{array}{r}8 \\
34 \\
42\end{array}$ \\
\hline
\end{tabular}

*Results in employees who had either a "positive" questionnaire $(n=\overparen{\mathbb{Q}}$ 8 ) or a change in $\mathrm{PC}_{20}(\mathrm{n}=7)$, or both, and who underwent inhalation challenges with spiramycin.

$\mathrm{PC}_{20}$, see footnotes to table 1 . 

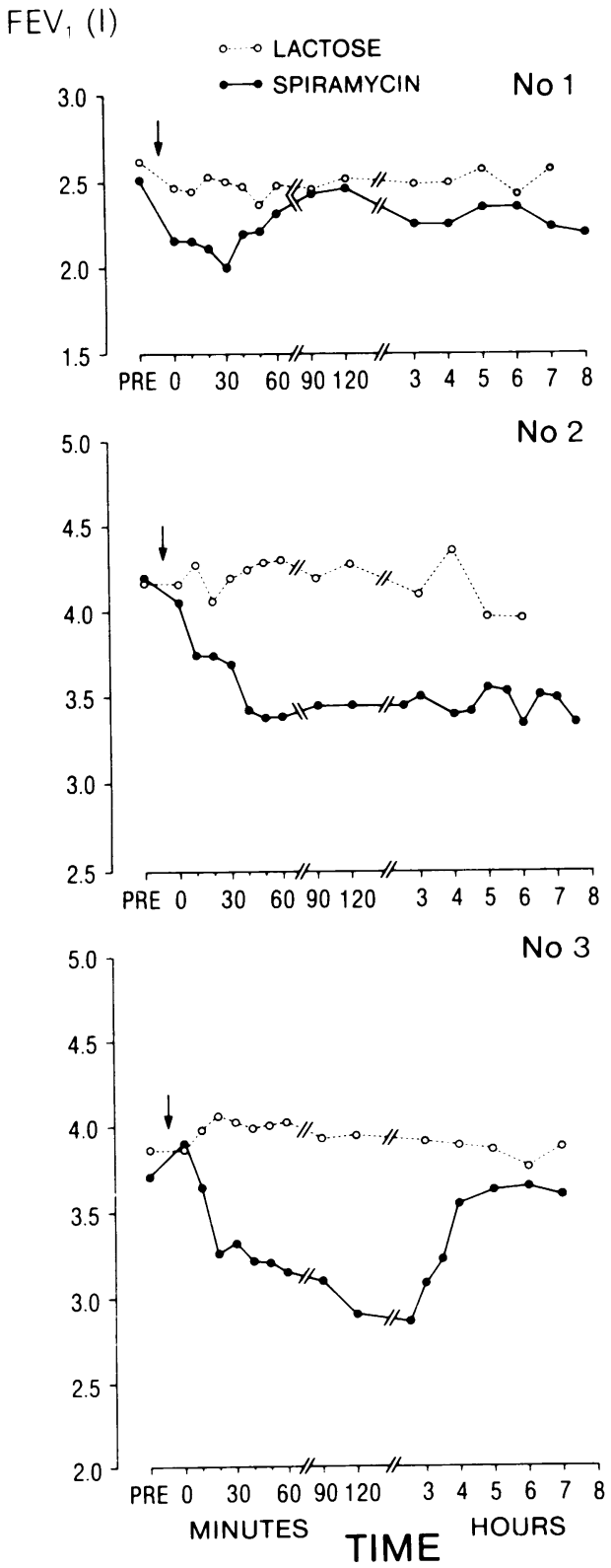

Results of inhalation challenges with spiramycin in the three subjects who showed bronchospastic reactions: isolated immediate reaction with a dubious late reaction in subject No 1 , immediate reaction without recovery in subject No 2 , and immediate reaction with late recovery in subject No 3. The arrows indicate the duration of exposure, which was 30 minutes in every case.

ma. ${ }^{5}$ Spiramycin is a macrolide antibiotic mainly used by dentists and veterinarians. We found evidence of occupational asthma to spiramycin in four out of 51
(7.8\%) employees of a pharmaceutical company, including the one in whom the diagnosis was made initially and three others in whom the diagnosis was confirmed in the present epidemiological survey. The prevalence of work related asthma in 305 workers exposed to spiramycin was $10 \%$ in a previous questionnaire survey, which did not use objective measures of pulmonary function and inhalation challenges. ${ }^{4}$ In the present study the diagnosis was made by inhalation challenges with spiramycin in the laboratory.

As only three subjects had occupational asthma due to spiramycin, risk factors and markers for the condition could not be determined with certainty. Two of the three subjects were smokers or ex-smokers and two were atopic.

In the present study the "gold standard" for confirming occupational asthma was the result of inhalation challenges with spiramycin in the laboratory. ${ }^{8}$ For these tests the maximum duration of exposure to spiramycin was set at 30 minutes. Although a longer period of exposure might have caused bronchoconstriction, this seems unlikely for the following reasons. Firstly, this duration of exposure was sufficient to elicit a reaction in one individual (No 3 ) who had no bronchial hyperresponsiveness to methacholine before the challenge. Secondly, there was no change in bronchial responsiveness to methacholine at the end of the active challenge day in any of the individuals considered to have negative responses to the challenges. Change in $\mathrm{PC}_{20}$ is more sensitive than spirometric change in detecting bronchial reactions after exposure to a sensitising agent. ${ }^{12}$

The bronchoconstriction which occurred in the three individuals in response to spiramycin appears to be specific and not due to an irritant effect. Similar exposure in the other four subjects with a $\mathrm{PC}_{20}$ under $16 \mathrm{mg} / \mathrm{ml}$ did not cause an appreciable change in $\mathrm{FEV}_{1}$. The pattern of the bronchoconstriction seen in two of the three subjects was not typical of IgE mediated reactions, where the maximum fall in FEV occurs 10-20 minutes after challenge with recovery in the first hour. Such immediate reactions might be followed by late reactions. ${ }^{8}$ More delayed reactions, such as those seen with spiramycin, have been described after exposure to agents like isocyanates, for which the mechanism of sensitisation is still debated. ${ }^{13}$

The mechanism of sensitisation to spiramycin could not be elicited as skin testing yielded anomalous results, some subjects with no occupational asthma reacting at low concentrations but not at high concentrations of spiramycin. A similar proportion of positive reactions occurred in a control group of asthmatic subjects. Skin testing with spiramycin has been used in previous investigations, and such reactions have not been noticed (the previous epidemiological survey, ${ }^{4}$ however, used only one concentration of spiramycin, $5 \mathrm{mg} / \mathrm{ml}$ ). As no dose-res- 
ponse curves were produced in previous studies, ${ }^{1-4}$ possibly anomalous reactions such as were observed in the present study were missed.

The findings of this study are relevant to the investigation of occupational asthma in employees exposed to a product for which skin testing is not feasible. The questionnaire administered before the production period did not suggest occupational asthma in the three individuals in whom the condition was proved by inhalation challenge. The questionnaire was, however, "positive" in the second assessment during the production period. Thus questionnaires should be administered at the time of exposure in individuals who are not continuously in contact with a sensitising product at work. Two of the three individuals with occupational asthma had a negative response to a methacholine test before the production period, and in one of the three the response was negative $(32 \mathrm{mg} / \mathrm{ml})$ even at the time of the production (table 2). Although bronchial hyperresponsiveness may persist for years after the end of exposure in subjects with occupational asthma,${ }^{14-17}$ such alteration in $\mathrm{PC}_{20}$ may be transient. ${ }^{18-20} \mathrm{We}$ found, however, that a fall in $P_{20}$ was present in the three individuals. These results show that the changes in $\mathrm{PC}_{20}$ may be as important as the absolute value of $\mathrm{PC}_{20}$ recorded during the production period.

The results of the present study suggest that a combination of a "positive" questionnaire and a fall in $\mathrm{PC}_{20}$ may be specific for the diagnosis of occupational asthma in an epidemiological survey for which exposure is intermittent. The three individuals with occupational asthma had both a "positive" questionnaire at the time of spiramycin production and a decrease in methacholine $\mathrm{PC}_{20}$. Responses to inhalation challenge with spiramycin were negative in the five individuals who had only a "positive" questionnaire and the four with only a decrease in $\mathrm{PC}_{20}$. We did not challenge the 30 subjects who had neither of these two features, as they were very unlikely to have occupational asthma. As we studied only about 50 workers and did not challenge every one with spiramycin, we are unable to assess the sensitivity and specificity of a questionnaire combined with determination of $\mathrm{PC}_{20}$ by comparison with the results of inhalation of spiramycin. This would warrant other studies as it is a relevant issue in the investigation of occupational asthma, as discussed by others. ${ }^{5}$

Our study suggests that the frequency of occupational asthma in workers exposed intermittently to spiramycin may be similar to that in red cedar and isocyanate workers, ${ }^{5}$ although this needs validation in larger surveys. A combination of a questionnaire and measurement of methacholine bronchial responsiveness may be the best way to detect individuals with occupational asthma when skin test- ing is not reliable, as is the case with several other low molecular weight agents.

We wish to thank the employer and employees in this pharmaceutical company for kindly consenting to collaborate in the present survey.

\section{References}

1 Davies RJ, Pepys J. Asthma due to inhaled chemical $\overrightarrow{ }$ agents-the macrolide antibiotic Spiramycin. Clin Allergy 1975;1:99-107.

2 Paggiaro PL, Loi AM, Toma G. Bronchial asthma and $\underset{x}{x}$ dermatitis due to spiramycin in a chick breeder. Clin $\vec{\omega}$ Allergy 1979;9:571-4

3 Moscato G, Naidi L, Candura F. Bronchial asthma due to spiramycin and adipic acid. Clin Allergy 1984;14:355-61.

4 Nava C. Rischi lavorativi da antibiotici: contributo allo studio della patologia professionale da spiramicina. Securitas $1976 ; 61: 275-80$.

5 Chan-Yeung M, Lam S. Occupational asthma. Am Rev Respir Dis 1986;133:686-703.

6 ATS statement. Snowbird workshop on standardization $\infty$ of spirometry. Am Rev Respir Dis 1979;119:831-8.

7 Cockcroft DW, Killian DN, Mellon JJA, Hargreave FE. Bronchial reactivity to inhaled histamine: a method and clinical survey. Clin Allergy 1977;7:235-43.

8 Pepys J, Hutchcroft BJ. Bronchial provocation tests in etiologic diagnosis and analysis of asthma. Am Rev Respir Dis 1975;112:829-59.

9 Knudson RJ, Lebowitz MD, Holberg CJ, Burrows B. Changes in the normal maximal expiratory flowvolume curve with growth and aging. Am Rev Respir Dis 1983;127:725-34.

10 Hetzel MR, Clark TJH. Comparison of normal and asthmatic circadian rhythms in peak expiratory flow rate. Thorax 1980;35:732-8.

11 Dehaut P, Rachiele A, Martin RR, Malo JL. Histamine dose-response curves in asthma: reproducibility and sensitivity of different indices to assess response. Thorax 1983;38:516-22.

12 Cartier A, L'Archevêque J, Malo JL. Exposure to a sensitizing occupational agent can cause a long-lasting increase in bronchial responsiveness to histamine in the absence of significant changes in airway calibre. $J$ 을 Allergy Clin Immunol 1986;78:1185-9.

13 Zammit-Tabona M, Sherkin M, Kijek K, Chan H, Chan- of Yeung M. Asthma caused by diphenylmethane diiso- $N$ cyanate in foundry workers. Clinical, bronchial N provocation, and immunological studies. Am Rev Respir Dis 1983;128:226-30.

14 Chan-Yeung M, Lam S, Koener S. Clinical features and natural history of occupational asthma due to western red cedar. Am J Med 1982;72:411-5.

15 Burge PS. Occupational asthma in electronics workers caused by colophony fumes: follow-up of affected workers. Thorax 1982;37:348-53.

16 Paggiaro PL, Loi AM, Rossi O, et al. Follow-up study of patients with respiratory disease due to toluene diisocyanate (TDI). Clin Allergy 1984;14:463-9. 
17 Hudson P, Cartier A, Pineau L, et al. Follow-up of occupational asthma caused by crab and various agents. J Allergy Clin Immunol 1985;76:682-7.

18 Hargreave FE, Ramsdale EH, Pugsley SO. Occupational asthma without bronchial hyperresponsiveness. Am Rev Respir Dis 1984;130:513-5.

19 Banks DE, Barkman W, Butcher BT, et al. Absence of hyperresponsiveness to methacholine in a worker with methylene diphenyldiisocyanate (MDI)-induced asthma. Chest 1986;89:389-93.

20 Mapp CE, Dal Vecchio L, Boschetto P, De Marzo N, Fabbri LM. Toluene diisocyanate-induced asthma without airway hyperresponsiveness. Eur J Respir Dis 1986;68:89-95. 